\title{
Multidimensional measure of aggression in adolescents: Croatian validation of the Peer Conflict Scale
}

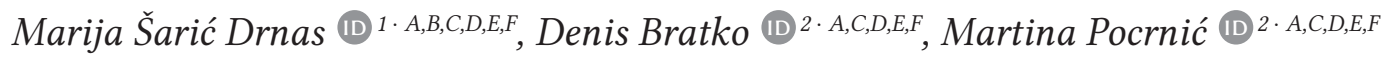 \\ 1: Department of Psychology, Faculty of Education, University of Zagreb, Zagreb, Croatia \\ 2: Department of Psychology, Faculty of Humanities and Social Sciences, University of Zagreb, Zagreb, Croatia
}

\section{BACKGROUND}

In order to adequately assess aggression in adolescence, the Peer Conflict Scale (PCS) was developed. It evaluates both forms and functions of aggression (i.e. proactive overt, proactive relational, reactive overt and reactive relational aggression). The goal of this study was to examine the validity and reliability of the Croatian version of the Peer Conflict Scale.

\section{PARTICIPANTS AND PROCEDURE}

The total sample consisted of 656 high school students from the City of Zagreb (age range 16-17, 55.33\% boys). Independent exploratory factor analysis (EFA) and confirmatory factor analysis (CFA) were conducted to determine the factor structure, and the best fitting model of the PCS on a Croatian sample.

\section{RESULTS}

Both results of EFA and CFA support a proposed fourfactor model of the instrument. Reliabilities of the instrument's scales were acceptable. The measurement invari- ance across gender was established. In order to analyse the construct validity of the PCS, relations between aggression subtypes and the theoretically meaningful variable, i.e. anxiety, were assessed. Reactive relational aggression had the highest correlation with anxiety, while proactive overt aggression did not correlate significantly with anxiety. Furthermore, gender differences in aggression subtypes were assessed, and were in accordance with past research.

\section{CONCLUSIONS}

Our study verifies the reliability, factor structure and construct validity of PCS in a sample of Croatian adolescents. However, the results of this study suggest that the response format should be changed. Furthermore, some items did not match well with corresponding factors and the best fitting model was the one in which those items were excluded. Therefore, we suggest that two items should be replaced with new ones.

KEY WORDS

aggression; CFA; EFA

Corresponding AUthor - Marija Šarić Drnas, Ph.D., Department of Psychology, Faculty of Education, University of Zagreb, Savska cesta 77, 10000 Zagreb, Croatia, e-mail: marija.saric@ufzg.hr

AUthors' CONTRIBUtion - A: Study design - B: Data collection - C: Statistical analysis - D: Data interpretation .

E: Manuscript preparation · F: Literature search · G: Funds collection

TO CITE THIS ARTICle - Šarić Drnas, M., Bratko, D., \& Pocrnić, M. (2020). Multidimensional measure of aggression in

adolescents: Croatian validation of the Peer Conflict Scale. Current Issues in Personality Psychology, 8(1), 61-72.

RECEIVED 07.10.2019 • REVIEWED 29.01.2020 • ACCEPTED 12.02.2020 • PUBLISHED 10.03.2020 


\section{BACKGROUND}

\section{FORMS AND FUNCTIONS OF AGGRESSIVE BEHAVIOUR}

Within a multidimensional approach to the study of aggression, scientists distinguish between different forms and different functions of aggression (Little, Jones, Henrich, \& Hawley, 2003; Marsee et al., 2011; Mathieson \& Crick, 2010; Ostrov \& Crick, 2007). Forms of aggression can be divided into overt aggression, which refers to endangering others by verbal and physical means, and relational aggression, which refers to endangering others through social relationships (Crick \& Grotpeter, 1995). Functions of aggression are classified according to the motive of the perpetrator (Tuvblad, Raine, Zheng, \& Baker, 2009). Accordingly, reactive aggression, which is described by the frustration-aggression hypothesis (Berkowitz, 1989), represents a hostile and defensive response to a perceived threat or provocation. Proactive aggression requires neither threat nor provocation. It represents instrumental, offensive, goal-directed behaviour, which is described by the social learning theory (Bandura, 1971).

There are several instruments designed to measure aggression, but only a few provide a comprehensive assessment of aggression that takes into consideration both the intention of the perpetrator, i.e., the function of aggression, and the manifestation of aggression, i.e., the form in which it appears. The first such measure was developed by Little et al. (2003). However, proactive and reactive aggression are insufficiently described with their items. All the proactive items measure aggression for gain (i.e., "To get what I want, I...") and all the reactive items measure aggression as a result of anger (i.e., "When I am mad at others, I...”). Studies on proactive and reactive aggression, besides gain and anger, also support other characteristics of these subtypes of aggression, such as premeditated aggression (proactive), domination (proactive), and impulsive aggression (reactive) (Dambacher et al., 2014; Stanford, Houston, \& Baldridge, 2008; Vitaro, Brendgen, \& Tremblay, 2002). Therefore, Marsee et al. (2011) designed a more comprehensive measure of aggression - the Peer Conflict Scale (PCS), which includes other measures of aggression such as aggression for dominance, sadism, unprovoked and premeditated aggression (Marsee et al., 2011). Thus, the PCS assesses four subtypes of aggression according to its form and function: proactive overt, proactive relational, reactive overt and reactive relational. Marsee et al. (2011) examined the psychometric properties of the PCS using a sample of adolescents in three different types of settings (school, residential intervention, and detention). The study showed that a model specifying these four aggression factors fits the data well across different types of settings for both boys and girls, with good internal consistency across samples, as well as expected correlations with externalizing variables.

\section{DIFFERENT CORRELATES OF AGGRESSION DIMENSIONS}

Studies show that the forms and functions of aggression are associated with different personality dimensions. Accordingly, proactive aggression is associated with low anxiety, callous-unemotional traits, and a disposition towards rewarding behaviour (Atkins, Osborne, Bennett, Hess, \& Halperin, 2001; Barry et al., 2000; Frick \& White, 2008). Reactive aggression is related to dispositions towards anxiety, emotional deregulation, and high emotional reactivity towards aversive stimuli (Vitaro et al., 2002). Overt aggression is related to a low predisposition to anxiety (Loukas, Paulos, \& Robinson, 2005; Terranova, Morris, \& Boxer, 2008), while relational aggression is related to a high predisposition to anxiety (Loukas et al., 2005). Thus, poor emotional regulation, such as high or low levels of anxiety, can influence the development of excessive aggression (Neumann, Veenema, \& Beiderbeck, 2010). Individuals who have a low propensity to anxiety have problems with internalizing social norms, which can lead to socially inappropriate behaviour, such as aggression (Dane \& Marini, 2014). On the other hand, high anxiety and aggression may co-occur because of shared risk factors such as difficult temperament, high autonomic arousal, and information-processing biases (Bubier \& Drabick, 2009). Further, gender differences in aggression consistently show that boys endorse higher levels of overt aggression, both proactive and reactive (Archer, 2004; Bailey \& Ostrov, 2008; Card, Stucky, Sawalani, \& Little, 2008; Lansford et al., 2012.; Marsee et al., 2011; Prinstein, Boergers, \& Vernberg, 2001) and that there are no gender differences in relational aggression.

However, these studies have chiefly focused on forms of aggression, and not on a combination of forms and functions (Card et al., 2008; Lansford et al., 2012; Prinstein et al., 2001). Most studies of proactive and reactive aggression correlates were based on overt forms of aggression. Thus, gender differences in aggression dimensions according to its form and function have not been sufficiently examined (Murray-Close, Ostrov, Nelson, Crick, \& Coccaro, 2011). For example, it was determined that boys score higher on proactive overt and reactive overt aggression (Bailey \& Ostrov, 2008; Marsee et al., 2011), while girls score higher on reactive relational aggression (Marsee et al., 2011), or no gender differences in functional types of relational aggression were determined (Bailey \& Ostrov, 2008).

In order to gain a more comprehensive understanding of the ways in which adolescent boys and 
girls aggress, as well as the motives of their aggressive acts, it is important to assess all four dimensions of aggression, which would help to identify different groups of aggressive youth who require different treatment approaches (Marsee et al., 2011). Forms and functions of aggressive behaviour are common among adolescents in diverse cultural contexts (Fung, Raine, \& Gao, 2009; Lansford et al., 2012; Tuvblad, Dhamija, Berntsen, Raine, \& Liu, 2016). Therefore, a reliable and valid instrument is needed for the assessment of aggression dimensions among adolescents. Thus far, the factor structure of the PCS has been validated in the United States, Portugal and Spain (Marsee et al., 2011; Perez-Fuentes et al., 2016; Vagos, Rijo, Santos, \& Marsee, 2014). In order to determine whether the PCS is suitable for adolescents from other cultures, more research is needed across diverse populations. Besides, there is no such instrument in Croatia that assesses both the forms and functions of aggression, so the present study intends to validate the PCS for the Croatian sample and to psychometrically evaluate the Croatian version of the instrument using a school-based sample of adolescents.

\section{THE PRESENT STUDY}

The first aim of this study was to validate the PCS using both exploratory factor analysis (EFA) and confirmatory factor analysis (CFA) in a general population of Croatian adolescents. EFA was conducted to determine the factor structure of the PCS. CFA was conducted to test the factorial validity by comparing the EFA suggested model and three measurement models as proposed by Marsee et al. (2011): a onefactor model (general aggression), a two-factor model (overt and relational aggression) and a four-factor model (proactive overt, proactive relational, reactive overt and reactive relational aggression). Additionally, a two-factor model distinguishing proactive and reactive aggression was compared. In line with previous findings (Little et al., 2003; Marsee et al., 2011; Vagos et al., 2014), we expect to replicate the fourfactor structure, which would have a good fit to the data for both boys and girls. The second goal of this study was to analyse the construct validity of the PCS by relating PCS aggression subtypes with anxiety and comparing aggression dimensions by gender. As previously stated, proactive and overt aggression are related to low anxiety, while reactive and relational aggression are associated with a predisposition to high anxiety. We aimed to use the Behavioral Inhibition System (BIS) from Gray's (1970) reinforcement sensitivity theory as the frame for measuring general anxiety. It has been shown that the BIS represents a neural substrate for the emotion of anxiety (Corr, 2008) and therefore we expected that anxiety operationalized through BIS would have differential association with different aggression types. Hence, we expected that proactive overt aggression would have the lowest relation with anxiety, while reactive relational aggression would have the highest relation with anxiety. Further, we expected that boys would endorse higher levels of overt aggression, both proactive and reactive. Since gender differences in functional types of relational aggression have not been sufficiently examined, no specific hypothesis about gender differences in functional types of relational aggression was made.

\section{PARTICIPANTS AND PROCEDURE}

\section{PARTICIPANTS}

The participants were third-grade students from secondary schools in the City of Zagreb, with an age range from 16 to 17 years. In total, 656 individuals completed the questionnaire, of whom $55.33 \%$ were boys. The sample was representative for the given age group in Zagreb since the research included seven different state schools - four gymnasiums and three schools with vocational technical programmes. Prior to the data collection, given the age of the respondents, active participant assent and passive parental consent were obtained, as well as the consent from the school principals and teachers. The study was approved by the Ethics Committee of the Department of Psychology at the Faculty of Humanities and Social Sciences in Zagreb. The data were collected in 2015, through the method of a self-report questionnaire, with the guarantee of anonymity. Participants were assessed in groups during their classes. Data collection sessions lasted approximately 30 minutes and were undertaken by the first author.

\section{MEASURES}

Peer Conflict Scale. The forms and functions of aggressive behaviour were measured through the Peer Conflict Scale (PCS; Marsee et al., 2011). The PCS is a self-report measure which consists of four subscales, each composed of 10 items designed to differentiate between proactive overt (e.g. "I enjoy hurting others"), proactive relational (e.g. "I enjoy making fun of others"), reactive overt (e.g. "If others make me mad, I hurt them"), and reactive relational aggression (e.g. "If others make me mad, I tell their secrets"). Responses are scored on a Likert scale in the range of 0 (not at all true) to 3 (definitely true).

Behavioural Inhibition System. Anxiety was measured using the Behavioural Inhibition System (BIS) subscale from the Sensitivity to Punishment and Sensitivity to Reward Questionnaire for Children (SPSRQ-C; Luman, van Meel, Oosterlaan, \& Geurts, 
2012). BIS measures general anxiety through eight items (e.g. "I often worry about things I said or did"). Responses are scored on a Likert scale in the range of 1 (I definitely do not agree) to 5 (I definitely agree). In this study, Cronbach's $\alpha$ coefficient of the BIS scale was .69.

Both PCS and BIS items were adapted into Croatian following a back-translation process which was undertaken by native speakers of English and Croatian. Firstly, the instruments were translated into Croatian and then they were translated back into English by an independent translator who was not familiar with the original instruments. In order to test the psychometric properties of the adapted versions of the questionnaires, a preliminary study was conducted on 81 third-grade students from a secondary school in Zagreb. The results of the preliminary study showed that the adapted instruments were appropriate for use in the main research.

\section{ANALYSIS}

Prior to conducting the main analysis, we examined the descriptive statistics of the scales and the normality of distributions by the Kolmogorov-Smirnov test and the values of skewness and kurtosis. In the first stage of the main data analysis, we conducted EFA to define the factor structure of the PCS. Since we aimed to perform independent EFA and CFA analyses, the total sample was split randomly into two independent groups: one for the EFA $(n=328)$, the other for the CFA $(n=328)$. The data for EFA were analysed via IBM SPSS version 20, using maximum likelihood factor analysis with oblique rotation (i.e., promax), since the four PCS aggression scales significantly correlate, with Pearson's correlation coefficients ranging from .39 to .69 .

In the second stage of the analysis, CFA was conducted using the software $\mathrm{R}$ (version 0.6-3) to compare the suggested EFA model and other theoretical models. In total, four models were tested: a one-factor model, a two-factor model with forms of aggression, a two-factor model with functions of aggression, and a four-factor model. Since PCS scales deviate from the normal distribution, the weighted least squares means and variance adjusted method was used for data analyses, being appropriate for CFA with categorical data. Prior to conducting the CFA, the last two response options on the PCS, "very true" and "definitely true", were collapsed into one category since girls did not use the option "definitely true" for five items. Collapsing the response options was necessary for establishing measurement invariance across gender groups since the number of categories should be the same on all items for both boys and girls in order to conduct gender group analysis (Marsee et al., 2011). Therefore, we used the best fitting CFA model to test for differences in the factor structure of the PCS across gender.

Finally, Pearson's correlation coefficients between PCS aggression subtypes and anxiety, and gender differences through $t$-tests were analysed for assessing construct validity.

\section{RESULTS}

\section{DESCRIPTIVE STATISTICS}

Descriptive statistics of the PCS for the overall sample, for boys and girls, are presented in Table 1, together with Cronbach's $\alpha$ coefficients for the whole sample. Distributions of aggression scales show positive asymmetry, which generally indicates a low representation of aggression among adolescents. The values of the Kolmogorov-Smirnov test for aggression scales range from 0.07 to $0.18(p<.01)$, while the values of skewness and kurtosis range from 0.21 to 1.46 , and from 0.35 to 2.39 respectively. Whereas in large samples standard errors of skewness and kurtosis decrease, indicators of skewness and kurtosis usually do not point to distribution symmetry

Table 1

Descriptive statistics for subscales of the PCS for overall sample, for boys and girls, and internal consistency values for overall sample

\begin{tabular}{|c|c|c|c|c|c|c|}
\hline & $\begin{array}{l}\text { Overall sample } \\
\quad(N=656)\end{array}$ & $\begin{array}{c}\text { Boys } \\
(n=363)\end{array}$ & $\begin{array}{c}\text { Girls } \\
(n=293)\end{array}$ & $t$ & $d$ & $\alpha$ \\
\hline & $M(S D)$ & $M(S D)$ & $M(S D)$ & & & \\
\hline PAO & $0.29(0.36)$ & $0.36(0.43)$ & $0.21(0.24)$ & $5.55^{* *}$ & 0.43 & .77 \\
\hline PAR & $0.34(0.36)$ & $0.35(0.37)$ & $0.33(0.34)$ & 0.51 & 0.05 & .75 \\
\hline RAO & $0.83(0.55)$ & $0.88(0.59)$ & $0.77(0.48)$ & $2.23^{*}$ & 0.21 & .80 \\
\hline RAR & $0.48(0.39)$ & $0.43(0.40)$ & $0.55(0.38)$ & $-4.75^{* *}$ & -0.31 & .75 \\
\hline
\end{tabular}

Note. PAO - proactive overt aggression; PAR - proactive relational aggression; RAO - reactive overt aggression; RAR - reactive relational aggression; ${ }^{*} p<.05,{ }^{* *} p<.01$. 
(Tabachnick \& Fidell, 2001). Internal consistency for the overall sample was acceptable, with $\alpha$ ranging from .75 for proactive relational, to .80 for the reactive overt aggression scale. The results show that proactive aggression manifests itself more often in a relational form $(t=-4.02, p<.01)$, while reactive aggression manifests itself more often in an overt form $(t=16.62, p<.01)$.

\section{EXPLORATORY FACTOR ANALYSIS}

Bartlett's test of sphericity $\left(\chi^{2}=5348.27, p<.001\right)$ and the KMO test (0.90) indicated that the correlation matrix was factorable. Therefore, assumptions for factor analysis were satisfied. According to the eigenvalues greater than 1 criterion and the scree test, a four-factor solution, which is interpretable and theoretically meaningful, sufficiently represents the data, explaining $44.90 \%$ of the variance.

Factor I consisted of 18 items and it may be labelled as relational aggression, while Factor II, which consisted of 15 items, may be labelled as overt aggression. Factors III and IV can refer to different functions of aggression and therefore they can be labelled as proactive aggression, which has 10 items, and reactive aggression with 7 items. Deeper inspection of the pattern matrix indicated that PCS aggression scales represent combinations of items of derived factors. Table 2 represents the factor loadings for the four-factor model of the PCS.

Accordingly, in line with expectations, the proactive relational aggression scale consisted of a combination of items from the relational aggression and proactive aggression scale, although item 2, which should represent the relational aggression type, has the highest loading on the overt aggression factor. Further, the reactive relational aggression scale consisted of items from the relational aggression and the reactive aggression scale, but a few items are additionally loaded on the proactive aggression factor as well. Items from the overt aggression and the proactive aggression scales can combinate to make the proactive overt aggression scale. However, items 33 and 35 load neither on the proactive nor the overt aggression scale, but only on the first factor, relational aggression. Finally, the reactive overt aggression scale consisted of items from the overt aggression and the reactive aggression scale. Overall, it can be stated that item loadings were mostly on the expected scales, with only a few exceptions, providing support for the predicted four-factor model.

Table 2

Factor loadings for the four-factor model of the PCS $(n=328)$

\begin{tabular}{|c|c|c|c|c|}
\hline \multicolumn{5}{|l|}{ Scale } \\
\hline Proactive Relational & I & II & III & IV \\
\hline 29. I spread rumors and lies about others to get what I want. & .82 & .10 & -.06 & -.11 \\
\hline 26. When I gossip about others, I feel like it makes me popular. & .77 & -.04 & -.12 & .07 \\
\hline $\begin{array}{l}\text { 6. I deliberately exclude others from my group, even if they haven't done } \\
\text { anything to me. }\end{array}$ & -.15 & .04 & .75 & -.06 \\
\hline 13. I tell others' secrets for things they did to me a while back. & .66 & -.04 & -.06 & .11 \\
\hline 23. To get what I want, I try to steal others' friends from them. & .59 & -.12 & .14 & .08 \\
\hline 19. I gossip about others to become popular. & .57 & .08 & -.14 & .26 \\
\hline 39. I say mean things about others, even if they haven't done anything to me. & .47 & -.06 & .15 & .10 \\
\hline 9. I try to make others look bad to get what I want. & .38 & .05 & .43 & -.16 \\
\hline 2. I enjoy making fun of others. & .02 & .37 & .34 & -.08 \\
\hline 32. I ignore or stop talking to others in order to get them to do what I want. & .22 & .16 & .31 & .06 \\
\hline Reactive Relational & I & II & III & IV \\
\hline 34. When others make me angry, I try to steal their friends from them. & .78 & -.01 & -.01 & -.15 \\
\hline 31. If others make me mad, I tell their secrets. & .73 & -.08 & .00 & -.12 \\
\hline $\begin{array}{l}\text { 17. When others make me mad, I write mean notes about them and pass them } \\
\text { around. }\end{array}$ & .66 & .21 & -.23 & -.02 \\
\hline 10. When someone upsets me, I tell my friends to stop liking that person. & .47 & -.09 & .20 & .16 \\
\hline
\end{tabular}


Table 2

(Table 2 continued)

\begin{tabular}{|c|c|c|c|c|}
\hline \multicolumn{5}{|l|}{ Scale } \\
\hline Reactive Relational & I & II & III & IV \\
\hline 15. I make new friends to get back at someone who has made me angry. & .47 & -.03 & .25 & -.05 \\
\hline 22. When I am angry at others, I try to make them look bad. & .46 & -.16 & .34 & .15 \\
\hline 4. Sometimes I gossip about others when I'm angry at them. & .16 & -.13 & .31 & .45 \\
\hline 7. I spread rumors and lies about others when they do something wrong to me. & .39 & .09 & .28 & -.01 \\
\hline $\begin{array}{l}\text { 38. Most of the times that I have started rumors about someone, I acted } \\
\text { without thinking. }\end{array}$ & .35 & -.32 & -.05 & .39 \\
\hline 40. When someone makes me angry, I try to exclude them from my group. & .30 & -.04 & .30 & .28 \\
\hline Proactive Overt & I & II & III & IV \\
\hline 28. I enjoy hurting others. & .08 & .77 & .06 & -.18 \\
\hline 1. I have hurt others to win a game or contest. & -.17 & .59 & .21 & -.02 \\
\hline 5. I start fights to get what I want. & -.02 & .20 & .58 & .02 \\
\hline 12. When I hurt others, I feel like it makes me powerful and respected. & .16 & .55 & .08 & .02 \\
\hline 18. I threaten others to get what I want. & .11 & .54 & .19 & -.31 \\
\hline 24. I carefully plan out how to hurt others. & -.03 & .54 & .20 & -.16 \\
\hline 33. I like to hurt kids smaller than me. & .51 & .23 & .04 & -.28 \\
\hline 21. I am deliberately cruel to others, even if they haven't done anything to me. & .28 & .14 & .46 & -.02 \\
\hline 27. I hurt others for things they did to me a while back. & .28 & .43 & .00 & .15 \\
\hline 35. I threaten others, even if they haven't done anything to me. & .39 & .23 & -.09 & -.11 \\
\hline Reactive Overt & I & II & III & IV \\
\hline 20. If others make me mad, I hurt them. & .04 & .82 & -.15 & .12 \\
\hline 16. Sometimes I hurt others when I'm angry at them. & .03 & .80 & -.15 & .14 \\
\hline 36. When I get angry, I will hurt someone. & -.13 & .66 & .09 & .20 \\
\hline $\begin{array}{l}\text { 30. Most of the times that I have gotten into arguments or physical fights, } \\
\text { I acted without thinking. }\end{array}$ & .00 & .17 & -.29 & .65 \\
\hline 11. I threaten others when they do something wrong to me. & -.15 & .57 & .20 & .27 \\
\hline 37. I have gotten into fights, even over small insults from others. & -.03 & .29 & .07 & .54 \\
\hline 25. When someone makes me mad, I throw things at them. & .20 & .51 & -.34 & .21 \\
\hline 3. When I am teased, I will hurt someone or break something. & .02 & .49 & .08 & .22 \\
\hline 14. When someone threatens me, I end up getting into a fight. & -.19 & .39 & .24 & .35 \\
\hline 8. When someone hurts me, I end up getting into a fight. & -.08 & .25 & .25 & .39 \\
\hline
\end{tabular}

\section{CONFIRMATORY FACTOR ANALYSIS}

Since the suggested EFA model was the same as the four-factor model proposed by Marsee et al. (2011), we compared four structural models to find the best factor structure of the PCS in a Croatian sample. Firstly, a one-factor model was specified in which all items loaded on a single factor. The results suggest that the PCS measures more than one dimension of aggression since this model showed inadequate fit $\left(\chi^{2}=1779.38, d f=740, p<.01 ; \mathrm{CFI}=0.84, \mathrm{TLI}=0.83\right.$, RMSEA $=0.07$, SRMR $=0.13)$. Guidelines for goodness of model fit (see Kline, 2015) suggest that for a good fit CFI and TLI indices should reach the value of .90, while RMSEA and SRMR should not exceed .05 and .10, respectively. Secondly, a two-factor model was specified in which items loaded onto two factors, overt and relational aggression, with 20 items 
each. This model showed improved fit $\left(\chi^{2}=1304.85\right.$, $d f=739, p<.01 ; \mathrm{CFI}=0.91, \mathrm{TLI}=0.91, \mathrm{RMSEA}=0.05$, SRMR $=0.10)$ compared with the one-factor model $\left(\Delta \chi^{2}=87.05, d f=1, p<.01\right)$. The third model was a four-factor model with items specified to load onto proactive overt, proactive relational, reactive overt, and reactive relational aggression factors. Each included 10 items. This model showed improved fit $\left(\chi^{2}=1194.52, d f=734, p<.01 ; \mathrm{CFI}=0.93, \mathrm{TLI}=0.92\right.$, RMSEA $=0.04$, SRMR $=0.10)$ compared with the two-factor model $\left(\Delta \chi^{2}=41.59, d f=5, p<.01\right)$. Finally, a two-factor model, distinguishing proactive and reactive aggression, was tested. This model exhibited inadequate fit $\left(\chi^{2}=1759.43, d f=739, p<.01 ; \mathrm{CFI}=0.84\right.$, $\mathrm{TLI}=0.83$, RMSEA $=0.07$, SRMR $=0.13)$ and the fourfactor model showed better fit $\left(\Delta \chi^{2}=216.02, d f=5\right.$, $p<.01)$. However, two item loadings on corresponding factors in the four-factor model were low: item 30 ("Most of the times that I have gotten into arguments or physical fights, I acted without thinking") and item 38 ("Most of the times that I have started rumors about someone, I acted without thinking") loaded on reactive overt factor .293 and reactive relational factor .299, respectively. Therefore, an additional model was included in comparison, namely a four-factor model with items 30 and 38 excluded. Excluding these items yields improved fit. Table 3 provides the fit statistics for all estimated models.

\section{TEST FOR INVARIANCE ACROSS GENDER}

The best fitting model, which was the four-factor model with items 30 and 38 excluded, was used to test for differences in the factor structure of the PCS across gender (Table 4). Models were fit separately within each group (boys, girls) prior to invariance testing. First, an unconstrained multigroup model was tested for boys and girls with factor loadings specified to vary freely across genders (configural invariance). This model had a good fit and the same loadings were significant for both groups, which means that configural invariance was established. This was a baseline model to which the other model was compared. Next, a model with all factor loadings constrained was tested and compared to the unconstrained model (metric invariance). The constrained model was not significantly different from the unconstrained model $\left(\Delta \chi^{2}=39.23, d f=34, p>.05 ; \Delta \mathrm{CFI}<.01\right)$, supporting the metric invariance of the four-factor structure across gender. Third, a model in which factor loadings and thresholds are constrained to be equal was fit to the data and compared against the metric invariance model (scalar invariance). The results indicate that full scalar invariance could not be achieved, because the constraints imposed by the model significantly worsen the model fit $\left(\Delta \chi^{2}=181.19, d f=34, p<.001\right)$. Examination of the modification indices suggested that PCS items 5 ("I start fights to get what I want"),

Table 3

Fit indices comparing CFA models for the Croatian version of the PCS $(n=328)$

\begin{tabular}{lcccccc}
\hline Model & $\chi^{2}$ & $d f$ & CFI & TLI & RMSEA & SRMR \\
\hline One-factor & $1779.38^{* *}$ & 740 & 0.84 & 0.83 & 0.07 & 0.13 \\
Two-factor (forms) & $1304.85^{* *}$ & 739 & 0.91 & 0.91 & 0.05 & 0.10 \\
Two-factor (functions) & $1759.43^{* *}$ & 739 & 0.84 & 0.83 & 0.07 & 0.13 \\
Four-factor & $1194.52^{* *}$ & 734 & 0.93 & 0.92 & 0.04 & 0.10 \\
Four-factor model with excluded items & $1053.91^{* *}$ & 659 & 0.94 & 0.93 & 0.04 & 0.10 \\
$\begin{array}{l}\text { Four-factor model with excluded items } \\
\text { on an overall sample }(N=656)\end{array}$ & $1520.39^{* *}$ & 659 & 0.90 & 0.90 & 0.05 & 0.08 \\
\hline
\end{tabular}

Note. CFI - comparative fit index; RMSEA - root mean square error of approximation; TLI - Tucker-Lewis index; SRMR - standardized root mean squared residual; ${ }^{* *} p<.001$.

Table 4

Multigroup gender analysis on the four-factor model (overall sample with excluded items)

\begin{tabular}{lccccccc}
\hline $\begin{array}{l}\text { Measurement } \\
\text { Invariance }\end{array}$ & $\chi^{2}$ & $d f$ & RMSEA & CFI & $\Delta \chi^{2}$ & $\Delta d f$ & $p$ \\
\hline Configural & 1901.28 & 1318 & 0.04 & 0.93 & & & \\
Metric & 1863.70 & 1352 & 0.03 & 0.94 & 39.23 & 34 & .246 \\
Scalar & 1992.55 & 1382 & 0.04 & 0.93 & 40.64 & 30 & .093 \\
\hline
\end{tabular}

Note. CFI - comparative fit index; RMSEA - root mean square error of approximation. 
Table 5

Factor loadings for the four-factor model (with excluded items) of the PCS $(n=328)$

\begin{tabular}{|c|c|}
\hline \multicolumn{2}{|l|}{ Scale } \\
\hline \multicolumn{2}{|c|}{ Proactive Relational } \\
\hline Item 29 & .91 \\
\hline Item 23 & .85 \\
\hline Item 9 & .77 \\
\hline Item 19 & .75 \\
\hline Item 26 & .73 \\
\hline Item 39 & .68 \\
\hline Item 13 & .62 \\
\hline Item 32 & .61 \\
\hline Item 2 & .58 \\
\hline Item 6 & .56 \\
\hline \multicolumn{2}{|c|}{ Reactive Relational } \\
\hline Item 34 & .89 \\
\hline Item 17 & .82 \\
\hline Item 7 & .76 \\
\hline Item 31 & .73 \\
\hline Item 15 & .72 \\
\hline Item 22 & .69 \\
\hline Item 10 & .65 \\
\hline Item 40 & .62 \\
\hline Item 4 & .47 \\
\hline
\end{tabular}

\begin{tabular}{|c|c|}
\hline Scale & \\
\hline Proactive Overt & \\
\hline Item 28 & .87 \\
\hline Item 27 & .83 \\
\hline Item 21 & .76 \\
\hline Item 12 & .76 \\
\hline Item 33 & .73 \\
\hline Item 18 & .71 \\
\hline Item 35 & .67 \\
\hline Item 24 & .61 \\
\hline Item 5 & .61 \\
\hline Item 1 & .51 \\
\hline \multicolumn{2}{|l|}{ Reactive Overt } \\
\hline Item 20 & .87 \\
\hline Item 16 & .81 \\
\hline Item 36 & .79 \\
\hline Item 11 & .72 \\
\hline Item 14 & .65 \\
\hline Item 3 & .65 \\
\hline Item 8 & .55 \\
\hline Item 37 & .50 \\
\hline Item 25 & .46 \\
\hline
\end{tabular}

Table 6

Correlations between PCS aggression subtypes and anxiety

\begin{tabular}{lccc}
\hline & \multicolumn{3}{c}{ Anxiety } \\
\cline { 2 - 4 } & $\begin{array}{c}\text { Overall } \\
\text { sample }\end{array}$ & Boys & Girls \\
\hline PAO & .02 & .07 & .00 \\
PAR & $.17^{* *}$ & $.20^{* *}$ & $.13^{*}$ \\
RAO & $.08^{*}$ & .10 & .08 \\
RAR & $.26^{* *}$ & $.30^{* *}$ & $.17^{* *}$ \\
\hline
\end{tabular}

Note. PAO - proactive overt aggression; PAR - proactive relational aggression; RAO - reactive overt aggression; $\mathrm{RAR}$ - reactive relational aggression; ${ }^{*} p<.05,{ }^{*} p<.01$.

16 ("Sometimes I hurt others when I'm angry at them") and 20 ("If others make me mad, I hurt them") were noninvariant across gender. Thus, a fourth model was tested (Gender-Partially Constrained) in which all thresholds were constrained except for thresholds of those items. This model was not significantly different from the unconstrained model $\left(\Delta \chi^{2}=40.64\right.$, $d f=30, p>.05$ ), generally supporting the invariance of the four-factor structure across gender (Table 5).

\section{CONSTRUCT VALIDITY}

Correlations between aggression subtypes and anxiety are presented in Table 6. In accordance with the hypothesis, proactive overt aggression had the lowest and non-significant relation with anxiety $(r=.02)$, while reactive relational aggression had the highest correlation with anxiety $(r=.26, p<.01)$. That pattern is manifested in the overall sample as well as independently for both boys and girls. Besides associations of PCS scales with the anxiety measure, the gender differences were also tested to establish construct validity and are presented in Table 1 . The obtained results showed that boys scored higher on proactive overt $(t=5.55, p<.01)$ and reactive overt 
aggression $(t=2.23, p<.05)$, while girls scored higher on reactive relational aggression $(t=-4.75, p<.01)$. The effect sizes of these differences are estimated as $d=0.43, d=0.21$ and $d=-0.31$, respectively. Results on aggression subtypes show that for boys there was no difference in use between proactive overt and proactive relational aggression $(t=0.62, p>.05)$, while reactive overt aggression was higher than reactive relational aggression $(t=15.17, p<.01)$. For girls, proactive relational aggression was higher than proactive overt aggression $(t=-7.50, p<.01)$ and reactive overt aggression was higher than reactive relational aggression $(t=8.08, p<.01)$.

\section{DISCUSSION}

The aim of the study was to validate the PCS on a Croatian sample using a secondary-school student population. According to internal consistency values, the PCS aggression scales showed acceptable reliability. Distributions of all aggression measures reflected positive asymmetry, which points to the generally low scores of aggression among adolescents. This is the expected result since our sample represents a secondary-school population, not a clinical or deviant one, e.g., children from detained settings. There is also a possibility that social desirability and biased self-perception played a role since aggression measures are highly influenced by socially desirable responding (Vigil-Colet, Ruiz-Pamies, AnguianoCarrasco, \& Lorenzo-Seva, 2012). Results from the overall sample show that proactive aggression manifests itself more often in a relational form, while reactive aggression manifests itself more in an overt form, which is consistent with past research (Kempes, Matthys, Vries, \& Engeland, 2005; Marsee et al., 2011). An explanation can be found in relation to social skills, where the association of social skills with proactive and relational aggression is positive, while the association of social skills with reactive and overt aggression is negative (Andreou, 2006; Dodge, 1991). In other words, with the help of social skills, proactive aggressive individuals tend to manifest aggression in a more hidden, relational way. Conversely, reactive aggressive individuals, due to their undeveloped social skills, rarely react in a relational way.

\section{FACTORIAL VALIDITY}

Our main goal was to validate the PCS using a combination of both EFA and CFA in a general population of Croatian secondary school students. EFA resulted in a suggested four-factor model, as proposed by Marsee et al. (2011). CFA also showed that the four-factor model had the best fit to the data. However, inspection of item saturation showed that items 30 and 38 have low correlations with their corresponding factors, reactive overt and reactive relational aggression, respectively. The content of these items refers to impulsivity, as was identified by Vagos et al. (2014). Although reactive aggression is related to a predisposition to impulsivity, these items do not represent a defensive reaction to a threat or a hostile reaction to a negative effect, which are the main characteristics of reactive aggression. Accordingly, we decided to include an additional model in the CFA analysis, a four-factor model with items 30 and 38 excluded. The exclusion of these items improved the fit to the data. The measurement invariance of that model has been established across gender, which implies that the observed mean differences can be attributed to differences in underlying constructs between gender (Hirschfeld \& Brachel, 2014). However, items 5, 16 and 20 did not exhibit scalar invariance across groups. Therefore, the interpretations of the meaning of these items are substantially different across gender. These items refer to overt aggression, which girls may interpret differently than boys.

Furthermore, in order to assess the measurement invariance, we had to collapse the last two response categories of the PCS since girls did not choose the extreme option for five items (items 17, 19, 23, 26 and 34). There is a noticeable trend that girls do not choose the "definitely true" option for all items in the PCS; this was also the case in the study of Marsee et al. (2011) and Vagos et al. (2014). A possible explanation of this trend can be found in the social role model approach (Eagly, 1987). According to the interpretation of gender differences, gender roles are internalized early in life through socialization processes, and shape how men and women should think, feel and behave. In our society, girls are more commonly taught from an early age that aggressive behaviour is not appropriate for their gender, while aggressive behaviour may be encouraged in boys. Accordingly, girls might be less prone to give extreme answers on PCS items given that aggressive behaviour is not compatible with their gender role.

\section{CONSTRUCT VALIDITY}

In order to analyse the construct validity of the PCS, we examined the associations between PCS aggression subtypes with the theoretically meaningful variable, anxiety, and compared aggression dimensions by gender. Past studies support associations of proactive, reactive, overt and relational aggression with anxiety. Marsee, Weems, and Taylor (2008) found that reactive relational aggression had the highest correlation with anxiety in comparison with other aggression subtypes, which is in accordance with the present results. Proactive overt aggression had the lowest correlation with anxiety while reactive relational aggression had the highest correlation with 
anxiety, which was observed for the overall sample and separately for boys and girls.

Gender differences in PCS subtypes provided additional analysis of construct validity. Accordingly, the results show that boys score higher on proactive overt and reactive overt aggression, which is in accordance with the findings that men are more overtly aggressive than women (Archer, 2004; Bailey \& Ostrov, 2008; Card et al., 2008; Lansford et al., 2012; Marsee et al., 2011; Prinstein et al., 2001). Further, girls score higher on reactive relational aggression, while there are no gender differences in proactive relational aggression. The obtained results are in accordance with the results of Marsee et al. (2011) and can be explained by different gender roles (Powell, 2009). The feminine role, which is characterized by the avoidance of conflicts and suppression of anger, can explain the lower manifestation of overt aggression among girls. The results also show that boys and girls manifest reactive aggression more in an overt form, and that girls manifest proactive aggression more in a relational form, while boys manifest proactive aggression similarly in both ways. This is in accordance with the results obtained by Vagos et al. (2014). The proactive aggression results can also be explained by gender roles, where girls tend to manifest their proactive aggression in a more hidden, relational way. To sum up, correlations between aggression subtypes and anxiety are in accordance with the hypothesis, and gender differences in aggression subtypes are in accordance with the results obtained by Marsee et al. (2011), all of which supports the construct validity of the PCS.

\section{LIMITATIONS AND CONCLUSIONS}

Although we have verified the strength of the Croatian version of the PCS in terms of reliability, factor structure and construct validity, there are some limitations to be taken into account when considering the study findings. Firstly, although large, our sample consisted only of third grade high school students. Therefore, it is doubtful that results from this study could be generalized to all adolescents, i.e. to other age groups. Furthermore, the BIS scale was used as the anxiety measure. Such operationalization is related in terms of content to the concept of sensitivity to punishment, and therefore it may be arguable as to what construct we measured. The Cronbach's $\alpha$ coefficient of the BIS scale was acceptable, but in a lower range (.69), which could have an influence on the size of the correlation coefficients with the PSC scales and on the conclusions on the construct validity of the PCS. Finally, we did not achieve full scalar invariance across genders since three items showed noninvariant thresholds. Thus, thresholds for these items were not constrained in the invariance analysis in order to improve the fit of the models across groups. However, the decision whether or not a measurement model exhibits measurement invariance is not an all-or-nothing decision. Partial measurement invariance describes cases in which only some indicators exhibit measurement invariance while others do not (Hirschfeld \& Brachel, 2014).

Despite the limitations, we have successfully validated the Croatian version of the PCS in terms of factorial and construct validity. This version may assist researchers in better understanding the results gained from the assessment of adolescents using the PCS. It may also aid in making improvements to the scale based on the suggestions arising from this research. Firstly, the "definitely true" option for some items in the study of Marsee et al. (2011), in a Portuguese validation of the PCS (Vagos et al., 2014) and in this study, was not endorsed by girls. This trend suggests that girls do not endorse extreme responses in the context of aggression. Therefore, in future studies the response options in the PCS should be changed. Furthermore, items 30 and 38, which refer to reactive overt and reactive relational aggression, respectively, had low loadings on corresponding factors. Analysis of item content indicates that these items represent impulsivity and not reactive aggression. So, the best fitting model in CFA was the one where those items were excluded. Due to this, we would suggest that these two items may be excluded or be replaced with ones that better fit the corresponding factors. Furthermore, the Croatian version of the PCS may be usable for clinical purposes in gaining a better understanding of adolescent aggression, whereby it can help in treatment programmes with adolescents. Intervention programmes could also benefit from the treatment of co-occurring low or high anxiety, which is an important factor in the manifestation of PCS aggression subtypes (Marsee et al., 2008). Further, this study has ascertained gender differences in aggression according to form and function, which is something that requires further examination (Bailey \& Ostrov, 2008; Marsee et al., 2011). This is also important for intervention programmes. Specifically, adolescents who manifest gender non-normative types of aggression have a greater risk of exhibiting behaviour problems. For instance, women who are overtly aggressive have more internalizing problems than men with the same type of aggression (Prinstein et al., 2001).

To sum up, our results validate the use of the Croatian version of the PCS in adolescents, based on its good psychometric properties as obtained in this study. The results of both EFA and CFA support the proposed four-factor model, which is invariant across gender groups. The PCS scales showed good reliability, as well as construct validity. Since there has been no multidimensional measure of aggression in the Croatian language so far, this instrument could be useful for Croatian researchers and practitioners who wish to obtain a more comprehensive assessment of aggression. 


\section{References}

Andreou, E. (2006). Social reference, perceived popularity and social intelligence - Relations to overt and relational aggression. School Psychology International, 27, 339-351. https://doi.org/10.1177/ 0143034306067286

Archer, J. (2004). Sex differences in aggression in real-world settings: a meta-analytic review. $R e-$ view of General Psychology, 8, 291-322. https://doi. org/10.1037/1089-2680.8.4.291

Atkins, M. S., Osborne, M. L., Bennett, D. S., Hess, L. E., \& Halperin, J. M. (2001). Children's competitive peer aggression during reward and punishment. Aggressive Behavior: Official Journal of the International Society for Research on Aggression, 27, 1-13. https:// doi.org/10.1002/1098-2337(20010101/31)27:1<1::aidab1>3.0.co;2-j

Bailey, C. A., \& Ostrov, J. M. (2008). Differentiating forms and functions of aggression in emerging adults: Associations with hostile attribution biases and normative beliefs. Journal of Youth and Adolescence, 37, 713-722. https://doi.org/10.1007/s10964007-9211-5

Bandura, A. (1971). Social learning theory. New York: General Learning Press.

Barry, C. T., Frick, P. J., DeShazo, T. M., McCoy, M., Ellis, M., \& Loney, B. R. (2000). The importance of callous-unemotional traits for extending the concept of psychopathy to children. Journal of Abnormal Psychology, 109, 335-340. https://doi. org/10.1037/0021-843x.109.2.335

Berkowitz, L. (1989). Frustration-aggression hypothesis: Examination and reformulation. Psychological Bulletin, 106, 59-73. https://doi.org/10.1037//00332909.106.1.59

Bubier, J. L., \& Drabick, D. A. G. (2009). Co-occurring anxiety and disruptive behavior disorders: The roles of anxious symptoms, reactive aggression, and shared risk processes. Clinical Psychology Review, 29, 658-669. https://doi.org/10.1016/j.cpr.2009. 08.005

Card, N. A., Stucky, B. D., Sawalani, G. M., \& Little, T. D. (2008). Direct and indirect aggression during childhood and adolescence: a meta-analytic review of gender differences, intercorrelations, and relations to maladjustment. Child Development, 79, 1185-1229. https://doi.org/10.1111/j.1467-8624.2008.01184.x

Corr, P. J. (2008). Reinforcement Sensitivity Theory (RST): Introduction. In P. J. Corr (Ed.), The Reinforcement Sensitivity Theory of Personality (pp. 1-43). Cambridge: University Press.

Crick, N. R., \& Grotpeter, J. K. (1995). Relational aggression, gender, and social-psychological adjustment. Child Development, 66, 710-722. https://doi. org/10.1111/j.1467-8624.1995.tb00900.x

Dambacher, F., Sack, A. T., Lobbestael, J., Arntz, A., Brugman, S., \& Schuhmann, T. (2014). Out of con- trol: Evidence for anterior insula involvement in motor impulsivity and reactive aggression. Social Cognitive and Affective Neuroscience, 10, 508-516. https://doi.org/10.1093/scan/nsu077

Dane, A. V., \& Marini, Z. A. (2014). Overt and relational forms of reactive aggression in adolescents: $\mathrm{Re}^{-}$ lations with temperamental reactivity and self-regulation. Personality and Individual Differences, 60, 60-66. https://doi.org/10.1016/j.paid.2013.12.021

Dodge, K. A. (1991). The structure and function of reactive and proactive aggression. In D. J. Peppler \& K. H. Rubin (Eds.), The development and treatment of childhood aggression (pp. 201-218). Hillsdale, NJ: Erlbaum.

Eagly, A. H. (1987). Sex differences in social behavior: a social-role interpretation. Hillsdale, NJ: Erlbaum.

Frick, P. J., \& White, S. F. (2008). Research review: The importance of callous-unemotional traits for developmental models of aggressive and antisocial behavior. Journal of Child Psychology and Psychiatry, 49, 359-375. https://doi.org/10.1111/j.14697610.2007.01862.x

Fung, A. L., Raine, A., \& Gao, Y. (2009). Cross-cultural generalizability of the Reactive-Proactive Aggression Questionnaire (RPQ). Journal of Personality Assessment, 91, 473-479. https://doi.org/ 10.1080/00223890903088420

Gray, J. A. (1970). The psychophysiological basis of introversion-extraversion. Behaviour Research and Therapy, 8, 249-266. https://doi.org/10.1016/00057967(70)90069-0

Hirschfeld, G., \& Brachel, R. (2014). Improving multiplegroup confirmatory factor analysis in $\mathrm{R}-$ a tutorial in measurement invariance with continuous and ordinal indicators. Practical Assessment, Research \& Evaluation, 19, 1-12. https://doi.org/10.7275/qazy2946

Kempes, M., Matthys, W., Vries, H., \& Engeland, H. (2005). Reactive and proactive aggression in children: a review of theory, findings and the relevance for child and adolescent psychiatry. European Child \& Adolescent Psychiatry, 14, 11-19. https:// doi.org/10.1007/s00787-005-0432-4

Kline, R. B. (2015). Principles and practice of structural equation modeling (3rd ed.). New York: Guilford Publications.

Lansford, J. E., Skinner, A. T., Sorbring, E., Giunta, L. D., Deater-Deckard, K., Dodge, K. A., ...Chang L. (2012). Boys' and girls' relational and physical aggression in nine countries. Aggressive Behavior, 38, 298-308. https://doi.org/10.1002/ab.21433

Little, T. D., Jones, S. M., Henrich, C. C., \& Hawley, P. H. (2003). Disentangling the "whys" from the "whats" of aggressive behavior. International Journal of Behavioral Development, 27, 122-133. https:// doi.org/10.1080/01650250244000128

Loukas, A., Paulos, S. K., \& Robinson, S. (2005). Early adolescent social and overt aggression: Examining 
the roles of social anxiety and maternal psychological control. Journal of Youth and Adolescence, 34, 335-345. https://doi.org/10.1007/s10964-005-5757-2

Luman, M., van Meel, C. S., Oosterlaan, J., \& Geurts, H. M. (2012). Reward and punishment sensitivity in children with ADHD: Validating the Sensitivity to Punishment and Sensitivity to Reward Questionnaire for Children (SPSRQ-C). Journal of Abnormal Child Psychology, 40, 145-157. https:// doi.org/10.1007/s10802-011-9547-x

Marsee, M. A., Barry, C. T., Childs, K. K., Frick, P. J., Kimonis, E. R., Munoz, L. C., \& Aucoin, K. J. (2011). Assessing the forms and functions of aggression using self-report: Factor structure and invariance of the Peer Conflict Scale in youths. Psychological Assessment, 23, 792-804. https://doi.org/10.1037/ a0023369

Marsee, M. A., Weems, C. F., \& Taylor, L. K. (2008). Exploring the association between aggression and anxiety in youth: a look at aggressive subtypes, gender, and social cognition. Journal of Child and Family Studies, 17, 154-168. https://doi. org/10.1007/s10826-007-9154-1

Mathieson, L. C., \& Crick, N. R. (2010). Reactive and proactive subtypes of relational and physical aggression in middle childhood: Links to concurrent and longitudinal adjustment. School Psychology Review, 39, 601-611.

Murray-Close, D., Ostrov, J. M., Nelson, D. A., Crick, N. R., \& Coccaro, E. F. (2011). Proactive, reactive, and romantic relational aggression in adulthood: Measurement, predictive validity, gender differences, and association with intermittent explosive disorder. Journal of Psychiatric Research, 44, 393-404. https://doi.org/10.1016/j.jpsychires.2009.09.005

Neumann, I. D., Veenema, A. H., \& Beiderbeck, D. I. (2010). Aggression and anxiety: Social context and neurobiological links. Frontiers in Behavioral Neuroscience, 4, 1-16. https://doi.org/10.3389/fnbeh. 2010.00012

Ostrov, J. M., \& Crick, N. R. (2007). Forms and functions of aggression during early childhood: a shortterm longitudinal study. School Psychology Review, $36,22-43$.

Perez-Fuentes, M., Mar Molero, M., Martos, A., Barragan, A. B., Gazquez, J. J., \& Sanchez-Marchan, C. (2016). Spanish analysis and validation of Peer Conflict Scale. European Journal of Education and Psychology, 9, 56-62. https://doi.org/10.1016/j.ejeps.2016.03.001

Powell, A. (2009). The relationship between femininity ideology and overt and relational aggression and peer victimization among girls. Electronic Theses and Dissertations, 522. https://digitalcommons. du.edu/etd/522

Prinstein, M. J., Boergers, J., \& Vernberg, E. M. (2001). Overt and relational aggression in adolescents: Social-psychological adjustment of aggressors and victims. Journal of Clinical Child Psychology, 30, 479-491. https://doi.org/10.1207/s15374424jccp 3004_05

Stanford, M. S., Houston, R. J., \& Baldridge, R. M. (2008). Comparison of impulsive and premeditated perpetrators of intimate partner violence. Behavioral Sciences \& The Law, 26, 709-722. https://doi. org/10.1002/bsl.808

Tabachnick, B. G., \& Fidell, L. S. (2001). Using Multivariate Statistics. New York: Allyn \& Bacon.

Terranova, A. M., Morris, A. S., \& Boxer, P. (2008). Fear reactivity and effortful control in overt and relational bullying: a six-month longitudinal study. Aggressive Behavior, 34, 104-115. https:// doi.org/10.1002/ab.20232

Tuvblad, C., Dhamija, D., Berntsen, L., Raine, A., \& Liu, J. (2016). Cross-cultural validation of the Reactive-Proactive Aggression Questionnaire (RPQ) using four large samples from the US, Hong Kong, and China. Journal of Psychopathology and Behavioral Assessment, 38, 48-55. https://doi.org/10.1007/ s10862-015-9501-2

Tuvblad, C., Raine, A., Zheng, M., \& Baker, L. A. (2009). Genetic and environmental stability differs in reactive and proactive aggression. Aggressive Behavior, 35, 437-452. https://doi.org/10.1002/ab.20319

Vagos, P., Rijo, D., Santos, I. M., \& Marsee, M. A. (2014). Forms and functions of aggression in adolescents: Validation of the Portuguese version of the Peer Conflict Scale. Journal of Psychopathology and Behavioral Assessment, 36, 570-579. https:// doi.org/10.1007/s10862-014-9421-6

Vigil-Colet, A., Ruiz-Pamies, M., Anguiano-Carrasco, C., \& Lorenzo-Seva, U. (2012). The impact of social desirability on psychometric measures of aggression. Psicothema, 24, 310-315.

Vitaro, F., Brendgen, M., \& Tremblay, R. E. (2002). Reactively and proactively aggressive children: Antecedent and subsequent characteristics. Journal of Child Psychology and Psychiatry, 43, 495-505. https://doi.org/10.1111/1469-7610.00040 